\title{
A Breakthrough Challenge with Tyre Waste Management: Thailand Perspective
}

\author{
Jiratchaya Duangburong, Supawan Tantayanon, and Paritud Bhandhubanyong
}

\begin{abstract}
The dynamic increase in the manufacture of tyre products, particularly those used in the automotive industry, is responsible for a huge amount of wastes, mostly in the form of used tyres, of which more than $\mathbf{2 0}$ million tonnes are produced globally each year. The widely differing chemical compositions and the cross-linked structures of rubber in tyres are the prime reason for highly resistant to biodegradation, photochemical decomposition, chemical reagents and high temperatures. The increasing numbers of used tyres therefore generate serious environmental problems. In this study we present the breakthrough challenge; access to knowledge and related technology, innovation and talented individuals residing internally and externally through the development of high quality, reliable and extensive networks with tyre waste management describing status of tyre waste and innovative organizational approaches in the management of used tyres in Thailand. As seen in the model of a Breakthrough Challenge with tyre waste management in Thailand, tyre wastes enter their end-of-life cycle after being brought to local car shops or garages by automobile owners. It was found that the primary technologies or innovations for tyre recycling and reuse in Thailand include heat utilization, tyre reclamation, tyre-derived aggregate and direct use.The possible uses of tyre waste as a source of innovative raw composite materials or high value added product in various industries such as plastic, automotive and construction industries are also discussed.
\end{abstract}

Index Terms-Breakthrough challenge, innovative raw materials, tyre waste management, high value product.

\section{INTRODUCTION}

Nowadays used tyre has become one of the largest scale rubber wastes. Recycle of the waste rubber is thus a great challenge for both environmental and economic reasons [1]-[3]. Tyre waste accumulations pose a threat to public health, safety, and the environment worldwide. This leads to further health and safety concerns when tyre piles are deposited near urban areas. Additional issues included discarded tyres destroying the aesthetics of a region or occupying large amounts of space in landfills due to the fact that tyres cannot be compacted unless they are shredded or otherwise mechanically degraded. The hazards associated with tyre wastes are amplified because of the sheer number of scrap tyres discarded per year worldwide. The worldwide generation of tyre waste is estimated at 1 billion tyres per year

Manuscript received May 1, 2014; revised July 17, 2014

Jiratchaya Duangburong and Supawan Tantayanon are with the Chulalongkorn University, Bangkok 10330, Thailand (e-mail: jiratchaya.nok@gmail.com).

Paritud Bhandhubanyong is with the Panyapiwat Institute of Management, Bang Talat, Pak Kret, Nonthaburi 11120, Thailand (e-mail: jiratchaya.nok@gmail.com).
[4]. This number is likely to increase, as the global tyre market is predicted to grow by approximately $5 \%$ over the period of 2011-2015.To manage the hazards associated with tyre waste, proper tyre waste management has become a necessity, but many nations are currently unable to process the overwhelming amount of waste tyres in an environmentally and economically sustainable manner. This is Thailand perspective, where the amount of tyre waste generated annually has been 400,000 - 600,000 tonnes. This number has recently increased significantly due to the nation's rapid motorization. Between 1993 and 2010, the number of motor vehicles sold in Thailand nearly doubled to over 700,000 vehicles, resulting in a dramatic increased in waste tyre generation [5].

In this study we present the breakthrough challenge; access to knowledge and related technology, innovation and talented individuals residing internally and externally through the development of high quality, reliable and extensive networks with tyre waste management. The status of tyre waste and innovative organizational approaches in the management of used tyres in Thailand will be described. The possible uses of waste tyres as a source of innovative raw composite materials or high value product in various industries such as plastic, automotive and construction industries will be discussed.

\section{THEORETICAL BACKGROUND}

\section{A. Technology and Innovation of Tyre Waste Management}

There are multiple technologies and Innovations for tyre waste management that, when properly executed, can be both safe and effective [6]-[8]. These technologies and innovations include landfilling, incineration for energy production, pyrolysis, grinding for various purposes, small scale reuse, retreading and recycling for innovative raw materials or high value added products.

\section{B. Breakthrough Challenge of Tyre Waste Management}

In order to study the breakthrough challenge caused by tyre waste, an effective tyre waste management system is critical. A tyre waste management system involves a number of different components [9]. The United Nations Environment Programme provides an extensive report on the definition and establishment of a general waste management program. This program serves as a framework for the structure of our report and provides a basis for our analysis and recommendations [10]. The United Nations highlights five key factors that must be present in order for a new waste management system to be established and have the potential for success. The factors are: 
- policies and regulations

- supporting institutions

- proper financial mechanisms

- stakeholder participation

- supporting technologies and innovations

The evaluation of tyre waste management technologies and systems resulted in several findings. We found that Thailand currently disposes tyre waste at a higher rate than the United States and Japan, and that the two nations that we used for comparison utilize multiple technologies other than disposal to manage tyre waste. We also discovered that Thailand has no regulations specific to the management of tyre waste, comparatively few available related statistics, and significantly less interaction between the government and private sector about the matter.

\section{Methodology}

Used in-depth interviews and field observations with 35 entrepreneurs and 8 innovative organizations approaches in the management of tyre waste in Thailand. To accomplish this goal we completed the following objectives:

- Characterize the tyre waste problem, existing practices, and potential management strategies specific to Thailand.

- Evaluate tyre waste processing technologies and innovations based on economic, social, environmental, political, and infrastructural factors applicable to Thailand.

- Evaluate potential tyre waste management systems for Thailand.

- Develop breakthrough challenge with tyre waste management in Thailand perspective.

\section{RESUlTS AND DisCUSSION}

According to our in-depth interviews and field observations, the results of the research are as follows:

\section{A. Characterize the Tyre Waste Problem, Existing}

Practices, and Potential Management Strategies Specific to Thailand

Thailand currently has 94 "sanitary" landfill facilities, along with hundreds of open and unrecognized dumpsites. According to the Thailand State of Pollution report from $2011,63 \%$ of all waste was improperly disposed of in open dump sites or openly burned. There are no municipal solid waste facilities dedicated solely to the purpose of tyre waste management in Thailand [11]. For tyre waste specifically, statistical data from the PCD shows that $63 \%$ of this waste is discarded or unaccounted for, $14 \%$ is reused as a tyre, $20 \%$ is reused in another form, and a small $3 \%$ is used to create energy. Statistically, the minority of tyre waste generated in Thailand are recycled or repurposed, exhibiting a critical need for the creation of a tyre waste management system. Countries with high tyre waste recycling and reuse rates tend to have integrated systems for waste management, which typically include regulations and laws, institutions, financial mechanisms, technology and infrastructure, and various stakeholders in the solid waste management chain. Developing systems to properly manage tyre waste, though initially costly, can become a profitable undertaking. Consequently, delaying the inevitable need to manage tyre waste can cause severe economic loss, as tyre fires and open dump sites can cost millions to clean up.

\section{B. Evaluate Tyre Waste Processing Technologies and Innovations Based on Economic, Social, Environmental, Political, and Infrastructural Factors Applicable to Thailand}

There are a number of tyre waste management technologies and innovations currently used in Thailand, many of which are commonly used on a global scale. However, in Thailand, the percentage of tyre waste that end up being disposed rather than repurposed is significantly higher than in nations with established tyre waste management programs.

1)Finding \#1: In Thailand, tyre waste are currently openly incinerated, dumped, and landfilled at high rates in comparison to nations with successful tyre waste management programs

Disposal of tyre waste through landfilling, open dumping, or open incineration are all problematic solutions to varying extents, due to the fact that they consume a useful resource without any benefit and have the potential to cause environmental harm. General disposal accounts for approximately $63 \%$ of all tyre waste in Thailand, though this statistic is not further separated into separate landfilling, open incineration, and open dumping categories. The full statistics can be viewed in Fig. 1.

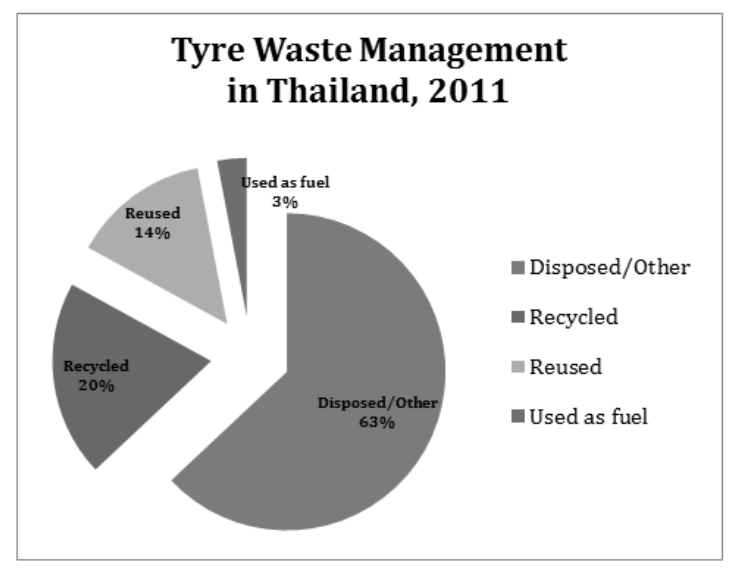

Fig. 1. Tyre waste management in Thailand.

In comparison, the United States and Japan dispose less than $15 \%$ and less than $10 \%$ of their tyre waste, respectively. The majority of the tyres disposed in the United States are landfilled, less than $13 \%$, and the only potential source of openly burned or dumped tyres is a minimal $2 \%$ of unaccounted for tyre waste. Japan's extremely low disposal rate is attributed to the fact that Japan is geographically small and highly industrialized resulting in the need to find alternative end of life uses for waste products and the technological means to support them. Japan also stands to benefit from solutions like reclamation of rubber, since the nation has no domestic rubber production industry. 


\section{2)Finding \#2: There are a number of viable tyre waste management technologies that could be applied in Thailand}

By evaluating the pros and cons of a variety of tyre waste management technologies and as illustrated by practices in Japan, the United States and elsewhere, many technologies are effective for managing tyre waste. Several technologies are currently, or have the potential to be, successful in Thailand, such as retreading, grinding for use in civil engineering practices, and reclamation for innovative raw materials and high value products for various industries.

\section{3)Finding \#3: Countries with successful tyre waste management practices employ multiple technologies to manage their tyre waste}

This strategy is advantageous because it lessens a nation's reliance on one tyre waste management method while also encouraging innovation and advancement in a range of technologies.

\section{Evaluate Potential Tyre Waste Management Systems for Thailand}

Currently, no specific laws concerning tyre waste management existed in Thailand. Instead, tyre wastes are defined to be part of municipal solid waste (MSW) and therefore must adhere to corresponding MSW regulations. However, our field observations and interviews indicate that tyre wastes are frequently treated separately from solid waste. At the same time, in less industrialized provinces, tyres are mostly dumped improperly in nearby forests and roads due to the lack of enforcement and monitoring from local agencies. Additionally, selling tyres for either reuse, recycling, or export is much more profitable than landfilling or open dumping. A lack of specific laws and regulations on tyre waste makes it harder for the government to keep track of various standards covering every stage of the tyre waste management life cycle stream.

\section{1)Finding \#4: Thailand currently has no laws or regulations specific to the management of tyre waste}

Currently, Thailand has laws and acts in place concerning solid waste management, which by default, encompasses tyre waste [11]. These policies include the Public Cleanliness and Orderliness Act, the Factory Act and the National Environmental Quality Act. Thailand is currently working to reach the goals laid out in this plan. While data is not yet available on the current status of these goals, a number of the plans do concern municipal solid waste as a whole, and therefore tyre waste. There are no laws or regulations in Thailand that are specific to tyre waste management yet. However, there are general regulations on air emissions and water pollution standards in Thailand. The present situation makes it difficult to monitor the total flow of tyre waste, and can, consequently, lead to unmonitored, transboundary diffusion of tyre waste. In addition, Thailand lacks local monitoring on various management steps, which prevents the PCD from keeping track of waste transfers between stakeholders in the system, and also overall execution and administration of all policies concerning tyre waste. This may lead to ambiguity in determining current status of the management system and probability and consequences of

\section{failure or mismanagement}

2)Finding \#5: Thailand's laws concerning the management of municipal solid waste are comparable to laws in nations with successful tyre waste management programs

Though Thailand does not have specific laws concerning tyre waste management, this lack of tyre-specific laws does not necessarily result in an inadequate tyre waste management system. Thus, Thailand's lack of specific laws related to tyre waste does not necessarily mean that successful management of tyre waste is inhibited.

3)Finding \#6: No agencies in Thailand which are responsible for collecting and reporting statistics concerning tyre waste management in Thailand

Typically, the institutions associated with tyre waste management are the national, state, and municipal authorities that are responsible for regulating the system. In comparison to the United States and Japan, comparatively few statistics concerning tyre waste management are available in Thailand. The statistics contained in this report, particularly those concerning processing technologies used in Thailand, were obtained on requested from the PCD. These statistics were also significantly less specific than similar statistics publicly available in the United States and Japan. Thailand's tyre waste management statistics are divided into the categories of "disposal", which consists of landfilling, open dumping, and incineration, "recycling", which includes reclamation, tyre-derived aggregate, and small-scale reuse projects. "Reuse", meaning the reuse of second-hand tyres or the retreading of waste tyres, and "tyre-derived fuel" through pyrolysis or incineration for energy. Comparative statistics from the United States and Japan break down these categories much more specifically.

\section{4)Finding \#7: At present, there is limited interaction between regulators and private businesses}

During our site visits, we were informed that tyre waste management facilities are inspected at least once a year by members of regulating institutions. There appears to be less interaction between the regulating institutions and private companies in Thailand than in either the United States or Japan.

Thailand lacks specific information on various management steps, starting from lack of collection centers. Thailand has a scattered tyre waste industry structure, where it can be difficult to obtain succinct information on enforcement of laws applying to tyre waste management.

5)Finding \#8: There is an established system of funding for Thailand's tyre waste management program, funded by the private sector

Through interviews with private company owners and automobile garage owners, we found that Thailand's tyre waste management program is largely funded by the private sector. The willingness of tyre waste businesses to purchase tyre waste led to the creation of the collection method that is currently used, which involves consumers giving or selling tyres to collectors, who then sell these tyres to the tyre waste management facilities. Automobile users typically bring their used tyres to garages, where they can either leave their waste 
tyres free of charge, or, depending on the garage, they may get credit toward a new tyre purchase or monetary compensation. This system is advantageous due to the fact that it rewards consumers or does not charge them for introducing their waste tyres into the recycling system, thereby discouraging the open dumping of tyres and encouraging recycling. It is also convenient for waste generators because the tyres can be collected at the point it is removed from the vehicle. As a method for comparison, in Japan, waste generators are allowed to contract with private businesses involved in waste collection, immediate treatment and final disposal. This industry has established a market of 2-4 trillion Yen (approximately 20-40 billion USD), representing 0.4-0.8\% Japan's GDP as of 2005.

6)Finding \#9: Information concerning the tyre waste management system is less available in Thailand than in nations with highly successful tyre waste management programs

Information concerning the tyre waste management system is much less available in Thailand than in the United States and Japan. This is likely due to the fact that the systems in the United States and Japan are more structured, meaning that information and statistics are more accurate and readily available. Additionally, Thailand does not seem to have one agency specifically responsible for collecting reliable statistics on tyre waste.

7)Finding \#10: Some stakeholders are presently unwilling or unable to participate in the tyre waste management system, or may be unaware how to effectively participate in the system

Globally, the types of stakeholders involved in tyre waste management are reasonably consistent. In Japan, the United States, and Thailand, the category of tyre waste producers is primarily comprised of vehicle owners, with some amount of contribution by tyre producers who will scrap low quality tyres. The collection methods are also somewhat standardized, though collectors in the United States and Japan must be registered, suggesting that tyre waste collectors in the United States and Japan are more highly regulated than those in Thailand. The end-of-life facilities are, again, comparable. Though standard operating procedures vary between the facilities, they have the same role in the tyre waste management chain.

\section{Develop Breakthrough Challenge with Tyre Waste Management Thailand perspective}

The above chart (Fig. 2) is a result of our findings regarding Thailand's tyre waste life cycle stream and will serve as a deliverable for this project. It includes all facets of the flow of tyre waste in Thailand, from the creation of the "Breakthrough Challenge with tyre waste management in Thailand" through its final repurposing or disposal.

As seen in the flowchart, tyre wastes enter their end-of-life cycle after being brought to local car shops or garages by automobile owners. It was found that the primary technologies or innovations for tyre recycling and reuse in Thailand include heat utilization, tyre reclamation, and tyre-derived aggregate and direct use. Some percentage of end-of-life tyres end up in landfills or are dumped openly in less industrialized provinces of Thailand. Although general information concerning disposal, reuse and recycling was available, no specific statistics concerning individual technologies were obtained, and no information on tyre waste management was available. Moreover, it is known that export of tyre waste is illegal in Thailand. However, through interviews and field observations, we have discovered that selling tyre waste to other countries in Southeast Asia is a profitable business.

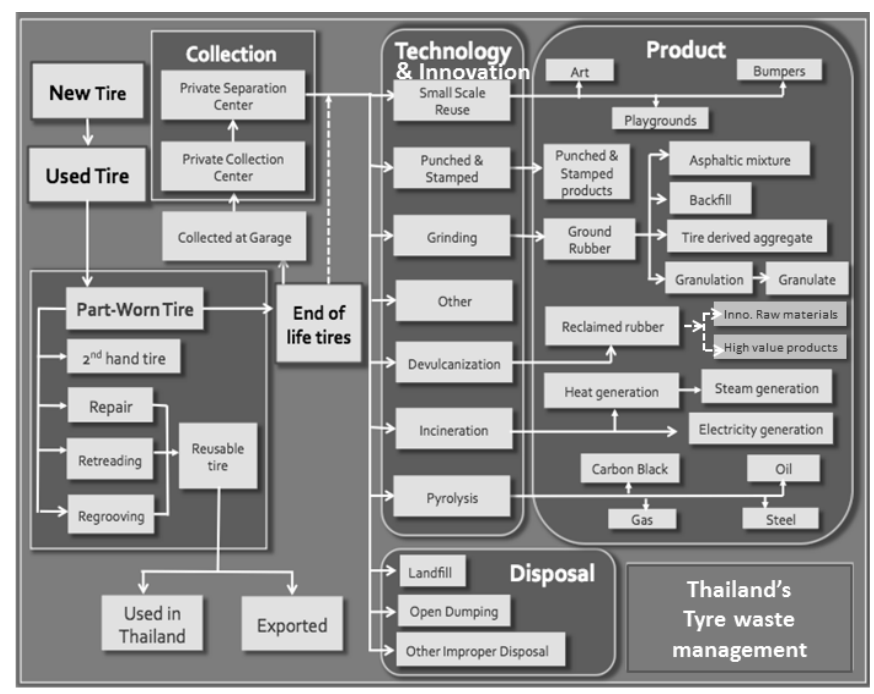

Fig. 2. A breakthrough challenge with tyre waste mangement: Thailand perspective model.

\section{CONCLUSIONS}

The findings, which are based on our independent research, evaluations of various technologies, and case study comparisons, have broadened our understanding of the current tyre waste management system in Thailand and the development of successful tyre waste management systems. The various aspects of Thailand's tyre waste management system, as defined by the UNEP, allowed us to draw conclusions based on our findings and present recommendations.

- Minimize the use of landfilling and eliminate the use of tyre waste mismanagement methods, notably open dumping and open incineration

- Expand the use of technologies that offer maximum economic and social benefit, with minimum environmental drawbacks, institutional requirements, and necessary regulation.

- Research and develop both emerging and established tyre waste management technologies.

- Develop an incubator company dedicated to sustainable tyre waste management on the government sectors.

- Establish and universally enforce tyre waste specific policies that establish guidelines for the tyre waste industry.

- Establish penalties for companies that fail to conform to newly-formed tyre waste management policies and incentives for businesses with environmentally considerate business practices.

- Increase cooperation between private sector and regulating institutions. 
- Expand public participation in the tyre waste management system through the use of a public education campaign.

- Further investigate information on public opinions and societal acceptance of a tyre waste of private sector growth in a free market economic system.

\section{REFERENCES}

[1] H. Purcell, "Tire recycling: research trends \& needs," Conservation and Recycling, vol. 2, no. 2, pp. 137-143, 1978.

[2] Y. Fang, M. Zhan, and Y. Wang, "The status of recycling of waste rubber," Materials and Design, vol. 22, pp. 909-948, 2001.

[3] M. Sienkiewicz, J. K. Lipka, H. Janik, and A. Balas, "Progress in used tyres management in the European Union: a review," Waste Management, vol. 32, pp. 1742-1751, 2012.

[4] J. William, S. Wongweragiatb, J. McGlinch, W. Bonawi-tand, and J. Choib, "An automotive bulk recycling planning model," European Journal of Operational Research, vol. 2, pp. 969-981, 2007.

[5] ETRMA. (May 2012). European Tyre \& Rubber Manufacturers' Association (Belgium) 2011. The Annual Report 2010/2011. [Online]. Available: http://www.etrma.org/default.asp

[6] B. Adhikari, D. De, and S. Maiti, "Reclamation and recycling of waste rubber," Prog. Polym. Sci., vol. 25, pp. 909-948, 2000.

[7] S. Juikam and S. Tantayanon, "Enhanced toughening polypropylene with reclaimed tire-rubber," J. Appl. Polym. Sci., vol. 91, no. 1, pp. 510-515, 2004

[8] P. Punnarak, S. Tantayanon, and V. Tangpasuthadol, "Dynamic vulcanization of reclaimed tire rubber and high density polyethylene blends," Polymer Degradation and Stability, vol. 91, no. 12, pp. 3456-3462, 2006.

[9] N. B. Chang, "Economic and Policy instrument analyses in support of the scrap tire recycling program in Taiwan," J. Environmental Management, vol. 86, pp. 435-450, 2008.

[10] UNEP. (May 2012). Developing Integrated Solid Waste Management Plan: Training Manual 2011. [Online]. Available:
http://www.unep.org/ietc/Portals/136/Publications/Waste\%20Manage ment/ISWMPlan_Vol2.pdf

[11] J. Sakulrat, S. Yuan, D. Mansell, and R. Darnsawasdi, The Key for Sustainable Municipal Solid Waste Management in Thailand, 2003.

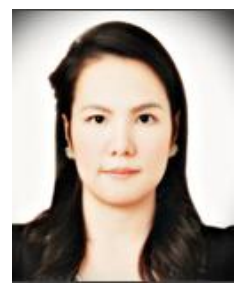

Jiratchaya Duangburong was born on December 3 , 1981, in Bangkok, Thailand. She received her B.Sc. in biotechnology and biomedical science, Mahido University, Thailand and received M.Sc. and Ph.D. in technopreneurship and innovation management, Chulalongkorn University, Thailand.

She is currently a manager (technology and innovation management sector) with the national science and technology development agency (government organization), ministry of science and technology, Thailand She have been spending years as a lecturer at MBA innovation management, Ramkhamhaeng University and has more than 12 years of technology and innovation management in tyre and green product industries.

Dr. Jiratchaya Duangburong has been awarded many times: Silver, true innovation awards (Thailand) 2010: Green product: New composite materials from tyre waste; $1^{\text {st }}$ Runner-up: Bangkok business challenge 2014 Business plan for green product: New composite materials from tyre waste Winner: Asia venture challenge 2014: Business plan for green product: New composite materials from tyre waste; Winner: New venture championship 2014 (Portland, USA): Business plan for green product: New composite materials from tyre waste; $1^{\text {st }}$ Runner-up: Global venture $L A B$ investment championship 2014 (Texas, USA): Business plan for green product: New composite materials from tyre waste; Winner: Global venture LAB investment championship 2014 (Texas, USA): Green product and clean technology [Wells Fargo awards]: New composite materials from tyre waste. And The patent is "Pending-Thailand Patent No.1201005348, material formulation for polypropylene/ reclaimed tyre rubber/sawdust composites, October 9, 2012". 